\title{
Epidemic Suicide in the Context \\ of Modernizing Social Change in Oceania: \\ A Critical Review and Assessment
}

Edward D Lowe

\begin{abstract}
On I2 February 1962, the New York Times reported on a visit to the island of Yap by Jose Antonio Benitez, the deputy high commissioner of the United States Trust Territory of the Pacific Islands (USTTPI). ${ }^{1}$ Benitez's mission was to announce a new policy of "Progress! Bulldozers! America!" (NYT I962). His announcement ended a period that the United Nations had criticized as "benign neglect" and began an era aimed at the rapid modernization of the region (Hezel I995). Over the next two decades, US development aid flooded into the USTTPI islands, rising from about US\$I I 7 per capita during the I 95 Os to a peak of about Us $\$ 4,738$ per capita by 1978 (Office for Micronesian Status Negotiations I984; amounts adjusted to $20 \mathrm{I} 8$ real dollars).

Within a few years, local ustTPI officials, Christian religious clergy, community workers, and traditional leaders began to express concern over the apparent social and psychological consequences of these economic development programs, particularly for adolescents and young adults (Hezel 1976, I977; Ward 2004). Their concerns would soon be validated as reports of increased public drunkenness, delinquency, peer violence, and suicidality among young people appeared across the region (Hezel I976, I977; Marshall I979; Rubinstein I983). Of these many serious social problems, epidemic increases in suicide rates were of particular concern. The Micronesian experience was not unique, as reports of rising suicide rates also appeared for other Pacific Island peoples (Gegeo and Watson-Gegeo I985; Haynes I984; Macpherson and Macpherson I987; Poole I 985 ). From the early I 980 os to the 2000 s, empirical epidemiologi-
\end{abstract}

The Contemporary Pacific, Volume 3I, Number I, I05-I38

(C) 2019 by University of Hawai'i Press 
cal evidence appeared to document and explain these problems specifically for Sāmoa and the Micronesian region. ${ }^{2}$ These studies became influential for a much broader literature concerning the psychosocial health effects of modernization and globalization on youth worldwide (Arnett 2002; Schlegel I995, 2013).

The increased vulnerability to mental health problems among Pacific Islands youth in the aftermath of late twentieth-century social changes is now widely recognized in the region. Current efforts aimed at addressing these problems include developing more innovative strategies and programs that are more culturally responsive than in the past. A critical component of the contemporary effort is to better understand concepts of wellness and ways of healing that have deep roots in Oceanic traditions and then to apply these to develop effective mental health programs and interventions (Mila-Schaaf 2006; Mila 2016). But it is also important in this effort to promote a more reflexive awareness of how explanatory accounts and models of mental illness that have their roots in European and North American experiences associated with the rapid growth of industrial society beginning in the nineteenth century have been appropriated and applied in the context of the Pacific Islands and to the contemporary Pacific Island peoples' experiences. Doing so will help us to place both Oceania's and Western medical knowledge systems on an equal footing by showing that each is embedded within a set of cultural assumptions and historical trajectories. Among the critical differences between the two knowledge systems is that Western models and accounts of illness emphasize, first, the internalization of societal norms and values that regulate selfish individual desires and, second, the establishment or maintenance of a meaningful place in a system of social roles or statuses. By contrast, perspectives common across Oceania's communities emphasize the importance of vā or wā, that is, "relationship, connection, space, distance, responsibility, obligation, state of being, position" (Mila 20I6, 70; also Lilomaiava-Doktor 2009). These two distinct perspectives suggest very different approaches for understanding social problems and for developing programs that can effectively address them.

The goal of this article, then, is to assess the main explanations that emerged in the I 980 and I 990 s to account for the late twentieth-century suicide epidemics in the island groups of Oceania for which the most data are available, with particular reference to the Republic of the Marshall Islands (RMI), the Federated States of Micronesia (FSM), and the 
Republic of Palau in the Micronesian region, as well as Sāmoa and Fiji. This assessment is important for furthering understandings of how modernizing and globalizing social change might or might not bring harm to local populations. But it also matters in terms of raising a greater reflexive awareness among scholars, practitioners, and activists of how long-enduring scholarly narratives that have their roots in the Western European and North American experience can shape our understandings of the other local worlds we seek to understand, sometimes with little regard for testing these models against the available evidence, including increasingly rich understandings of wellness in Oceanic societies in their own terms (Browne and others 20I4; Taualii and others 20II; Taualii, Delormier, and Maddock 20I3; Taualii and others 2014). An increased self-awareness among researchers about their own use of traditional scholarly theories and models is an important step toward developing more culturally and historically relevant suicide prevention strategies in specific Pacific Islander societies (Stewart-Withers and O'Brien 2006; Mila 20I6).

To this end, I begin with a discussion of the most influential nineteenthcentury European theories of how social change associated with the transition to modern societies might worsen vulnerability to suicide (notably Durkheim I95 I [1987]), followed by a review of selected literature concerning well-documented suicide epidemics in Sāmoa, Fiji, and Micronesia, in which I show how the explanations in this literature reflect those already put forward by Durkheim. I then present a critical assessment of these explanations using selected statistical evidence associated with the specific aspects of modernizing social change that are believed to increase vulnerability for particular groups within a population, such as older adolescents and young adults. In doing so, I do not intend to address the growing recent literature of the psychosocial correlates of suicidal ideation and behavior among individuals, indigenous or nonindigenous, in the Pacific Islands region (eg, Peltzer and Pengid 2015). Rather, my focus is on the literature that has emerged to document and explain epidemic suicide rates in several Pacific Island nations and regions over a forty-year period from the I970s to the 2000 s. $^{3}$ The discussion here is sociological in nature, following Durkheim's distinction between social facts like suicide rates, whose causes are understood to reflect collective social phenomena, whereas individual cases reflect highly idiographic and more complex causal configurations. 


\section{Durkheim in Oceania: Theories of Social Change and Suicide EpIDEmics}

In this section, I briefly review Western sociological models of social change and suicide that developed fully in the late nineteenth century, particularly as articulated by Durkheim, which I argue have strongly influenced the literature for this topic. Some scholars are explicit about Durkheim's direct influence on their work (eg, Hollan I990; Tousignant I998), while others draw from mid-twentieth-century translators of Durkheim like Robert K Merton (eg, Macpherson and Macpherson I987, 2009). In most other cases, the influence of nineteenth-century theorists like Durkheim is implicit. After I present an overview of Durkheim's theory, I show how these accounts based on Durkheim-inflected models of causation have been applied to different explanations for suicide in specific Pacific Island cases.

Over the course of the nineteenth century, suicide rates became a signal indicator for how modernizing social change might worsen mental health and social functioning for vulnerable people in Europe and the United States (Giddens 1965; Hacking I990; Lowe 2017, 2018). One of the earliest social science literatures developed in order to document suicide rates and identify particularly vulnerable groups in terms of age, gender, marital status, social class, religion, and geographical location (eg, Morselli i 879; see Giddens 1965 for a review). The main sociological model of modernizing social change that theorists used to explain differences in suicide rates between nations and between particular groups within nations in Europe was already well established when Durkheim published Le Suicide in I 897. What Durkheim added to previous models was a more complete theory of how the mechanisms that accompany modernizing social change might increase risks for suicide for particular groups in society. It is important to note that these theories did not suggest that modernizing social change as such was negative; rather, they looked at specific processes associated with modernizing social change that could be harmful. Here, I focus on the two main processes that were clearly described by Durkheim: social disequilibrium and social disintegration.

In Le Suicide, Durkheim argued that, while suicidal behavior could be found in all societies, both the rate of suicide and its causal meaning reflected specific societal variables. In industrial or industrializing societies, where individuals are caught between consciousness of their own individual interests and awareness of their social dependence on others in 
the division of labor, suicide is typically either anomic or egoistic, reflecting two distinct explanatory dimensions. The first dimension (anomie) emphasizes the social processes that affect the internalization of cultural norms and values. The second dimension (egoism) represents social processes that relate to the integration of individuals into a society's formal institutions. As societies changed from traditional to modern, Durkheim argued that anomic and egoistic suicides would become more common.

\section{Social Disequilibria and Anomic Suicide}

Anomic suicides result from the failure of a society's collectively shared norms and values to effectively regulate its members' desires and the amount of personal satisfaction gained from social participation (Durkheim I95I). Durkheim characterized this as a form of social disequilibrium. In Durkheim's view, and following a well-established explanatory account in European philosophy since the Enlightenment, human desires for power, wealth, and status (or any other of life's satisfactions) are potentially limitless. However, these desires cannot possibly all be met given limitations inherent in nature and society. While early experiences with natural limitations can help individuals learn strategies for delayed or deferred gratification, the internalization of cultural values and norms provides an essential source of restraint for individuals' desires and expectations. So long as members believe that these standards for differential rates of sacrifice and satisfaction are just, members do not suffer an exaggerated sense of dissatisfaction, frustration, or unhappiness. However, if collectively held norms and values lose their capacity to restrain desires, the constant, socially produced imbalance between individual expectations and actual satisfactions contribute to constant frustration and unhappiness and, at the collective level, lead to the increase of suicide as one means of alleviating psychic pain among members of the society whose social position leaves them vulnerable to mental health problems.

Anomic suicide is thought to be particularly characteristic of newly modernizing societies because they are prone to periods of dramatic economic booms and busts. During times of sudden economic change, a state of social disequilibrium would emerge where extant norms and values no longer fully justify either the increased rates of return for some members of society or the suddenly decreased rates of return for others. During these times, increased psychosocial distress-marked by frustration, indignant anger, and even hopeless despair-could result from either a sudden loss of one's inherited or achieved material security, status, or financial 
accomplishments, or an increased awareness that new opportunities for personal gain (along with new, competing beliefs and values) were increasing, but that one was unjustly blocked from realizing these opportunities because of one's position in society and the now "old-fashioned" norms and values associated with that position.

\section{Social Disintegration and Egoistic Suicide}

Egoistic suicides, on the other hand, reflect vulnerable individuals' low levels of social integration into a society's collective institutions, such as kin, occupational, political, or religious groups. This explanation emphasizes the integration of individuals into a social structure, rather than the internalization of collectively held norms and values. Social integration affords to a society's members a strong feeling of being a part of a group that they love and promotes a willingness to defer personal desires for those of others. Suicide is less likely in these groups because an individual is less likely to follow his or her own impulses toward self-harm without first considering its impact on others. Social integration also affords a society's members a sense that others love and support them, both morally and practically. Thus, during times of need or psychological exhaustion or duress, individuals who are well integrated into social institutions are more likely to believe in and seek out the support of the group (Durkheim I95I, 209-210).

Durkheim argued that active membership in a well-integrated society and participation in its collective institutions provide a sense of transcendent purpose and meaning. This sense of transcendence allows a society's members to better cope with the existential understanding that, as selfaware, mortal beings, "all of our efforts will end in nothingness, since we ourselves disappear," which "terrifies us" (Durkheim I95 I, 2 IO). Without membership in a well-integrated society, "one would lose the courage to live, that is to act and struggle, since nothing will remain of our exertions" (Durkheim I95 I, 210). Members of a well-integrated group can derive some peace from the belief that their efforts will live on in the lifetimes of other group members who outlive them.

Theoretically, modernizing social change can lead to social disintegration, particularly for traditional institutions organized through kinship. As new, modern institutions replace those that had once been organized through community rituals and expansive forms of kinship, the modern nuclear family becomes the dominant form of kinship (Kuper 2005). As 
a result, individuals must increasingly forge their own identities independently of the wishes of their kin and home community, often by voluntarily pursuing a role in any number of new, modern institutions such as formal occupations, political organizations, and voluntary organizations that become available. For Durkheim, social disintegration leads to something like a psychological mood disorder on a collective level: it is "a sort of collective asthenia, or social malaise, just as individual sadness, when chronic, in its way reflects a poor organic state of the individual" (Durkheim I95 I, 2I4). Without countervailing factors in a society, these conditions make suicide more likely, increasing the overall rate.

It is important to note that the preceding model suggests a rather pessimistic view of how modernizing social change might relate to suicide and related ills, given an absence of protective factors. Other early theorists of modernity, like Georg Simmel (2002 [1903]), celebrated modernizing social change, particularly that found in the industrial metropolis, for its unprecedented opening of possibilities for personal independence and individual self-expression, in contrast to the oppressive social relations in preindustrial societies in Europe and elsewhere.

\section{In Durkheim's Shadow: Theories of Social Change and Suicide in Selected Pacific Island Societies}

Given that Durkheim is rarely cited explicitly, it is striking how well the historical literature concerning modernizing social change and suicide epidemics in several well-known cases such as Sāmoa, Fiji, the Marshall Islands, Federated States of Micronesia, and Palau in Micronesia fit into his model. ${ }^{4}$ Much of the existing literature for Sāmoa and Fiji emphasizes the problems facing adolescents and young adults who have come of age during a period of dramatic social, political, and economic change on their home islands. These changes are thought to be distributed unevenly, introducing social disequilibria that leave young people vulnerable to anomic suicides. The Micronesian literature emphasizes the effects of a dramatic decline in the organization of kinship beyond the level of individual nuclear family households and how these changes undermine the social integration of young people into their families, kin groups, and communities, particularly in the case of older boys and young men. Vulnerability to egoistic suicide is argued to be the result. I now review each of these literatures briefly. 


\section{Social Disequilibrium for Sāmoa and Fiji}

Social disequilibrium models are dominant in the explanations of suicidality for Sāmoa and Fiji. ${ }^{5}$ Consider the following quote from Tim O'Meara:

The correlation of the suicide epidemic with the rapid modernization of the post-independence era in Western Samoa is no accident. The desires and expectations of young people are changing very fast. Radios, movies, television, videos, and New Zealand-style education give people new ideas and new dreams. Perhaps most importantly, the dramatic increase in overseas migration and travel has opened up a different, and in many ways very attractive, world of new possibilities. The closeness of that other world sometimes makes patience difficult, yet the actual pace of social and economic change makes the fulfillment of the expectations very unlikely. Rapid social change alone is not the problem. Suicide is uncommon in American Samoa, where change has been far more rapid and dramatic than in Western Samoa... . The real problem appears to be uneven change, specifically the lag between young people's growing expectations and social and economic realities in which they live. (I990, I IO-I I I, emphasis in the original)

Although O'Meara's research focused primarily on economic changes in rural Sāmoa during the late I970s and early I980s, the timing of his research and widespread public concern about rising suicide rates (described in Bowles 1985, 1995) did not escape O’Meara's notice. His statement reflects a common explanation offered for suicide and social change at that time, particularly as it reflects the experiences of young men (Booth I999b; Schlegel 1995, 2013). A similar explanation is given for high rates of suicide among Fiji Indians at about the same time (Haynes I984).

However, during its suicide crisis in the I970s and I980s, Sāmoa was atypical because the rates for female youth were nearly as high as those for males (Booth I999b; Bowles I985, I995; Macpherson and Macpherson 1987,2009$)$. And among young adult Fiji Indians in Fiji, suicide rates for females exceeded those of males in the I980s (Booth I999a, 4I). Worldwide, in contrast, male suicide rates are typically three or four times greater than female rates (World Health Organization I999, 20I4). Drawing on the available ethnographic accounts for Fiji (Counts I984) and Sāmoa (Macpherson and Macpherson I987; Schoeffel I979), Heather Booth offered an explanation for the observed gender differences for Sāmoa and for Fiji Indians, arguing that the traditional pathways to meaningful adult identities are fundamentally different for males 
and females in most Pacific Islander societies (1999a). The pathways for power and status among young women traditionally operate through a combination of sexuality, marriage, and childbearing. For young men, on the other hand, power and status is a product of their socioeconomic standing and record of socially valued achievements (see also Schlegel I995, 2013). Young adult socialization in these Pacific Island communities has traditionally guided young men and young women along different paths according to these different, normative, and valued socialization goals. As a result, the impact of social change on the well-being of youth depends on whether and how social changes transform these gendered pathways into a socially and culturally valued adulthood. Booth argued that, for young women, modernizing change promotes a lowered value on the achievement of traditional women's roles, instead placing increased importance on autonomously deciding one's future (I999a). This challenges traditional gender norms and forms of power, often leading to authoritarian and punitive responses from parents or in-laws and increasing a sense of powerlessness and frustration for older girls and young women. For young men, modern values emphasize education and economic achievement in the formal employment sector. But, when economic growth lags behind growth in educational opportunities, the shortfall between individual expectations and actual possibilities for economic achievement in the local formal employment sector heightens the perception of powerlessness among many older boys and young men (Booth I999a, 6I; Macpherson and Macpherson I987, 2009).

More recently, social disequilibrium models have been amended to allow for bidirectional flows between traditional and globalizing norms and values. In a widely cited 2002 essay, Jeffrey Arnett argued that young people should develop local/global hybrid identities as a way to successfully adapt to the forces of globalization that they encounter. Those who are unable to do so, Arnett suggested, are at greater risk for poorer mental health and suicide. Thomas McDade and Carol Worthman proposed a model somewhat between Arnett's balanced hybridity and older social disequilibrium models (McDade and Worthman 2004). Rather than an exclusive focus on the development of hybrid psychosocial identity, they theorized in more general, nested terms, including attention to the psychological, social, cultural, and institutional features of the contexts of growth and socialization. They proposed that "socialization ambiguity" may contribute to the problems of young people in places like Sāmoa. Socialization ambiguity occurs when they are confronted by conflicting 
institutionalized socialization practices about the relative value of localtraditional and global-modern norms, values, and goals related to adult identity pursuits.

The models proposed by both Arnett and McDade and Worthman offer a more complicated picture of how local and global normative systems and young people's opportunities for achievement can interact to decrease or increase mental health vulnerabilities. Those who participate in communities that remain committed to many of their core local cultural values, particularly values that define moral behavior within the context of reciprocity in the family and kin group, can be at greater risk for frustration and confusion when these localized values conflict with the values and opportunities present through participation in modern institutions like school, global media, and modern transnational markets. In these contexts, exposure to globalizing, modern values in addition to local values opens a great variety of items, activities, and opportunities to youth and their families. These models suggest that young people who can somehow resolve these ambiguities suffer less than those who are unable to do so.

\section{Social Disintegration in Micronesia}

Working from suicide case data and extensive ethnographic and personal experience in Micronesia, Francis Hezel (1987, 1989) and Donald Rubinstein (1992, I995, 2002) argued that social and economic changes in the region led to the breakdown of lineage groups, making young men particularly vulnerable to social marginalization and suicide. Hezel observed that suicides in this region are usually precipitated by family conflict, reasoning that something within the dynamics of Micronesian kinship at the level of families must be responsible for the increased rates of suicide across the region (1987, 1989). He argued that these family troubles were primarily the result of the transformation of kin groups from lineage-based organizations to nuclear families. This transformation in the social organization of kin was promoted by the rapid growth of the cash economy in the former USTTPI islands that began in the early I960s (Hezel I995).

According to Hezel, from the I960s to the I980s Micronesian Islander households had much greater direct access to wage work and were, as a result, able to purchase more imported food such as rice and tinned meats for their basic daily needs (1987, I989). Before this time, most islander households relied on the cooperative productive labor of lineage mates or in-laws to harvest and prepare the produce of starchy tree and root crops 
(eg, breadfruit, yams, taro) and protein products that they fished or collected from the reefs. The cooperative labor of the extended kin group fell under the direction and authority of lineage segment heads or lineage chiefs. As wage-based productive labor and associated expenditures came under the greater control of parents as household heads, the cooperative adult labor that held lineage-level organizations together diminished. The authority of lineage-level leaders also diminished while that of nuclear family heads such as parents and eldest siblings increased.

As a result, young people came to rely more on their parents and older siblings for their various needs and permissions, while the youth of earlier generations had a much wider range of adult kin to count on for support. Since access to highly valued manufactured goods is limited in Micronesia, and youth have become largely dependent on their parents to purchase them, tension and conflict between young people and their parents became more common. At the same time, weakened lineage structures left youth with fewer supportive ties to other adults who could mediate intergenerational conflicts. Hezel concluded that this combination of increased tension within the reinforced nuclear family and the narrowed scope of adult supports in the weakened lineages contributed greatly to the suicide epidemic in Micronesian societies and probably also in the Samoan case (1987, 1989). Importantly, Hezel emphasized that, while social complexity in terms of the organization of kin groups decreased (ie, nuclear families became more common), the internalization of traditional norms and values that emphasize the central importance of devotion to family and wider kin groups remained as important as ever throughout Micronesia. Indeed, the attachment to these historically durable norms and values may contribute to the frustration that socially marginal members of kin groups, like young men, experience all too often. Had more modern, globalizing values associated with personal autonomy and independence from the family taken hold, the social and structural changes in the organization of kin groups may not have resulted in such a dramatic rise in suicide rates after the I960s (Hezel, pers comm, 20I7; see also Hollan I990 for a similar example from the Toraja of Sulawesi).

Rubinstein placed many of Hezel's observations in a human-developmental framework (Rubinstein I983, I992, I995, 2002). Rubinstein has characterized the traditional pattern of Micronesian socialization as centrifugal: At certain critical periods of children's development in Micronesia, structural and relational tensions emerge in the prior caregiving arrangement that are culturally managed by encouraging children to shift 
their attachments from current caregivers to others within the wider kin group (Rubinstein I987, 1992; see also Lowe 2002, 2003). So, after receiving care from their mothers in infancy, their fathers and older siblings provide the bulk of child care until about age twelve. At about puberty, the extended kin group of cousins, aunts, and uncles is increasingly significant. As a teenager, a young person is likely to spend significant time away from his or her natal family, even traveling for extended periods to live with relatives on nearby islands. Finally, with marriage, attachments extend to one's spouse and affinal kin. The overall goal of these traditional socialization experiences is to produce an individual who becomes increasingly interdependent (as opposed to autonomous and independent) within a wide-ranging set of kin, often including members of his or her mother's matrilineage first, his or her father's matrilineage second, and to a spouse's lineage third.

The period of social adolescence in many Micronesian contexts, spanning roughly from the onset of sexual maturity until marriage and childbirth, can be particularly difficult for teenaged boys and young men. During this period, the relationship between brothers and sisters becomes one of avoidance and reserve (Gladwin and Sarason 1953; Rubinstein I992). As a means of managing this culturally sensitive period, males are typically expected to move out of their natal family household. Before the twentieth-century colonial period, older teenage boys and young men would typically take up residence in a lineage meetinghouse, a lineageowned bachelor's clubhouse, or live in the houses of extended kin who had no classificatory sisters. Teenage girls and young women typically stayed close to their natal households.

Traditionally, economic roles for male and female youth were markedly different. Girls and young women's productive activities became focused on household chores like tidying the house, gathering and preparing food, and helping to care for younger children. Boys and young men often participated with their brothers and cousins in peer-related activities, such as learning local martial arts, and with their uncles, fathers, and grandfathers in wider lineage or lineage-segment level activities, like planting and maintaining gardens, fishing beyond the reef, and building or repairing houses, cookhouses, and other lineage structures.

This pattern of activity enabled girls and young women to maintain closer relationships with their parents and the other adults of their natal households, while boys and young men were more dependent on support from men of their wider matrilineage. Thus, this period of their lives 
was often one of greater social and economic insecurity for male youth. These insecurities are often found in recorded cases of suicidal behavior in the early ethnographic literature for Chuuk Lagoon (eg, Gladwin and Sarason I953). Young men's insecurities seem to diminish after marriage when they are once again firmly part of and productively contribute to a domestic household.

Rubinstein argued that, by the end of the Second World War, many of the traditional lineage-level institutions and related activities were abandoned across the former USTTPI island groups, while the practices associated with brother-sister avoidance had remained in place (I992). Males who came of age in the postwar period (starting about 1965 or so) were particularly vulnerable to the deep insecurities that resulted from the expectation that they would avoid their sisters and, by extension, their natal households at the same time as they lacked access to the other lineage-based social supports that young men had been able to rely on in the past. Left in a state of increased social marginality, young men would continue to be vulnerable to suicide until new social and cultural adjustments emerged that would allow them to become better integrated into the new, contemporary family forms in Micronesia (Rubinstein 1995). Conversely, as Hezel emphasized, young women remained better integrated into their family and wider kingroups as their social position remained secure throughout adolescence and into adulthood (1987, 1989; pers comm, 2017).

While Hezel and Rubinstein have concentrated on social disintegration and the loss of social supports for young men in Micronesia, other work has addressed the existential problems that social disintegration can create. Anthony Marsella, Ayda Austin, and Bruce Grant proposed a general theory for suicide and other forms of psychosocial distress in Pacific Island societies where rapid social and technological changes can lead to the disintegration and dislocation of social and cultural forms that, they believe, "have endured for generations" $(2005,274)$. Echoing Durkheim, they argued that the resulting loss of tradition rends the social fabric that binds members of the societies together into productive and healthful systems of meaning, leading to increased incidence of psychosocial pathology.

\section{Does Available Evidence Support the Durkheimian Narratives?}

As discussed in the preceding section, much of the scholarship at the end of the twentieth century and start of the twenty-first concerning social 
change and suicide epidemics, particularly for Sāmoa and the Micronesian region, strongly reflects Western sociological theory as it was articulated by Durkheim at the end of the nineteenth century. The general pattern in these studies was to document the trends in suicide rates and then apply well-accepted variants of this Western theory to explain those trends. However, empirical evidence was rarely presented to test the adequacy and relevance of these arguments in the Pacific Island contexts (see Macpherson and Macpherson 1987, 2009; Bowles 1985, I995 for exceptions). This section draws on evidence from epidemiological reports as well as national and regional census reports from Sāmoa and Micronesia-the best-documented cases of late twentieth-century suicide epidemics in the region-to empirically assess the main claims of both the social disequilibrium and the social disintegration hypotheses. This analysis is intended to be suggestive, not conclusive, as the latter would require much more formal methodological procedures (eg, Lowe 20I8).

First, while rapid social and cultural change associated with the intensified globalization has been widespread throughout the Pacific Islands region since at least the early I970s and has continued to the present (Firth 2000), suicide rates are highly variable across Pacific Island nations (Booth I999b; World Health Organization 20I4). Of course, some of the reported variability may be a result of the varying reliability of suicide documentation in different countries. But rates are highly variable even in those cases where great care was taken in the collection of epidemiological data. Consider the suicide rates for Sāmoa and Micronesia as reported in Table I. These statistics represent my calculations for changes in estimated crude suicide rates from the mid-I960s to the early 2000 s. ${ }^{6}$ For Sāmoa, about a decade after national independence in 1962, suicide rates rose sharply, from between 4 and 7 per I00,000 in the early I970s to 31 per I00,000 in I98 I. ${ }^{7}$ After that time, suicide rates in Sāmoa declined sharply. Using Terry Bourke's reported incidence of suicide and population estimates available from the World Bank (200I), one finds an average, unstandardized crude suicide rate of I 2 per I00,000 for Sāmoa for I988-I992, below the world average of 16 per I00,000 in the mid-I990s (World Health Organization I999). During the 200I-2005 period, using data from the Samoan Ministry of Health (2005), the estimated crude suicide rate for Sāmoa was 8 per I00,000, also well below the world average. Of course, these official reports may miss a considerable number of suicides. But, assuming the Samoan Ministry of Health continues to use procedures that were devel- 
oped to systematically survey and document suicide in the I980s (Bowles I985, I995), it is likely that these numbers are reliable. Moreover, I would emphasize that the change in the epidemic rate of suicide should in no way diminish the importance of this endemic problem in Sāmoa and the ongoing need for suicide prevention and treatment programs, particular for young people who are most vulnerable to suicide and other mental health problems (Samoan Ministry of Health 2005).

The Micronesian region presents a contrasting case. Table I shows that suicide rates across the region increased sharply from the late I96os, with an average of 3.8 per 100,000 in I964-1967, until the I980s, when rates peaked at an average of 30.33 in the 1980 to 1983 period. However, these rates remain stubbornly above world averages up to the $200 \mathrm{I}-2005$ period, with the average for the six island polities listed being 23.8 per I00,000 in the I993-1996 period and 22.3 in the $200 \mathrm{I}-2005$ period. Suicide rates in the two most populous island polities, Chuuk State and Pohnpei State of the Federated States of Micronesia, did decline to below the world average by 200I-2005. More recent epidemiological data for the Micronesian region and Sāmoa were not available at the time of this writing. ${ }^{8}$

TAв Le I Average Multiyear Suicide Rates for Micronesian Island Groups and Sāmoa, I960-2005

\begin{tabular}{lrrrcccc}
\hline & Palau & Yap & Chuuk & Pohnpei & Korsae & Marshalls & Sāmoa \\
\hline I960-63 & 23 & 7 & 2 & 0 & 0 & 0 & $\ldots$ \\
I964-67 & 9 & 0 & 6 & 2 & 0 & 6 & $\ldots$ \\
I968-7I & 2 I & I9 & IO & 3 & 7 & I2 & 5 \\
I972-75 & I 8 & 43 & 26 & I 8 & 0 & 20 & 7 \\
I976-79 & 25 & 4 I & 3 I & 22 & I7 & 20 & 20 \\
I980-83 & 30 & 60 & 39 & II & I9 & 23 & 24 \\
I984-87 & 29 & 20 & 28 & I7 & 26 & 27 & I3 \\
I988-92 & 29 & 48 & 35 & 20 & 28 & 26 & I2 \\
I993-96 & 2 I & 4 I & 28 & 24 & 2 & 26 & I3 \\
I997-00 & 30 & 27 & 2 I & 2 I & I6 & 27 & IO \\
200I-05 & 24 & 3 I & 9 & I4 & 33 & 23 & 8 \\
\hline
\end{tabular}


Assessing the Evidence Associated

with Social Disequilibrium Explanations

The Samoan pattern of sharp increases and equally sharp declines in suicide rates from the I970s into the 2000 s particularly requires attention because, even though suicide rates have declined, many of the factors associated with the social disequilibrium theory persist today, such as rising expectations gained through increased access to secondary and tertiary education, Western media, and opportunities to migrate abroad mixed with few local, modern economic opportunities. As an example, consider the ongoing disequilibrium between increasing educational achievement and lagging opportunities for economic achievement in Sāmoa. According to data available from Sāmoa's Population and Housing Census 201 I, in the rural island of Savai'i and the rural districts on Upolu that are away from the urban center of Apia, about 75 percent of the population aged fifteen years and older had attained at least a secondary level of education (Samoa Bureau of Statistics 20II). Yet only about 40 percent reported being economically active and, of these, over half in rural Upolu and nearly two-thirds in Savai'i were active in subsistence work as opposed to the wage economy. In Apia, 88 percent of residents fifteen years and older had attained at least a secondary level of education, yet just under half (48 percent) were economically active, nearly all (90 percent) employed in the wage economy. This suggests that a relatively stable set of social and economic circumstances cannot be a deciding factor in the highly variable rate of change in suicide rates during the Samoan suicide epidemic of the I970s and early I980s or in their dramatic decline in the mid-I980s through the early 2000 s.

It is not likely, either, that the sharp decline in suicide rates in Sāmoa after the mid-r980s was the result of a sudden increase in outmigration of young people seeking work in New Zealand, American Sāmoa, and elsewhere in the region or beyond. Since the I970s, outmigration from Sāmoa has remained substantial, with the World Bank estimating that net outmigration has been at a relatively constant rate of between 7 percent and II percent since the I970s (20I4). Cluny Macpherson, Richard Bedford, and Paul Spoonly reported that the main motivations for migration have been the pursuit of greater educational opportunities and economic stability since the I950s (2000).

An imbalance between levels of educational achievement and local economic opportunities in formal labor markets has been a persistent feature 
of the socially and culturally more diverse Micronesian region. FSM, RMI, and Palau census reports dating back to the I950s allow for a longitudinal look at how expanding educational opportunities outpaced economic opportunities in the wage and salaried employment sector over the second half of the twentieth century (such a long-range view is not possible for Sāmoa, where comparable data for this period are lacking). The 1958 Census of the Trust Territory of the Pacific Islands reports that, across the different Micronesian island groups, less than 2 percent of adults over the age of twenty-five were high school graduates (USTTPI I958). By the I980 USTTPI census, the rate of high school graduation had improved for adults twenty-five and older from a high of 44 percent in Kosrae to a low of about I 4 percent in Chuuk (US Bureau of the Census [1984]). High school graduation rates would improve further by the mid to late 2000s, with a low of 28 percent in Chuuk and higher rates of 59 percent for Yap and 70 percent for Palau. Population growth was rapid during this period. Population across the former USTTPI island groups (the Marshall Islands, the Federated States of Micronesia, and Palau) increased from about 62,000 in 1958 to about 178,000 in the mid-2000s. So, the improvement in educational attainment reflects a dramatic increase in capacity to educate growing numbers of children and adolescents during this period.

A very different picture emerges when one examines patterns for economic opportunities over this period. What is striking is how little the relative proportions of the population employed in wage/salary jobs and working in agricultural or subsistence work have changed since the late I950s. For example, in 1958, the percentage of working age adults (aged fifteen or older) employed in wage- and salary-based occupations ranged from 16 percent in Pohnpei to about 22-25 percent for Chuuk and Kosrae and about 30-34 percent for Palau and Yap (USTTPI I958). Those working in subsistence, market agriculture, or home manufacture (including copra, farming, and handicrafts) ranged from 6-8 percent in Palau and Pohnpei, to 20-27 percent in Kosrae, the Marshalls, and Chuuk, to a high of 54 percent in Yap. Across the UstTPI region in I958, about 23 percent were employed in wage or salary occupations and about 20 percent were employed in agricultural or subsistence occupations. Preparing copra made up the lion's share of the latter activities. By I980, employment for those fifteen years and older in wage or salary jobs ranged from I 8 percent in Chuuk, to around 25 percent for Yap, Pohnpei, Kosrae, and the Marshalls, and 39 percent for Palau. Across the region in I980, nearly identical percentages of working-age adults were employed in wage/salary 
jobs ( 22 percent) or subsistence-level jobs only ( 25 percent) (US Bureau of the Census [1984]). Across the region in 2010, now exclusive of Palau for which data are not available in 2010 or $20 \mathrm{II}$, about 25 percent of residents were employed in wage or salaried jobs while about 20 percent were engaged in subsistence-level work (FSM Division of Statistics 20I 2; Republic of the Marshall Islands 20I2).

So, the trend across the Micronesian region from the late I950s to the present is one of apparently increasing disequilibrium between educational attainment and local economic opportunities in the contemporary wage and salaried sectors. Reports indicate that the same trend has been true for Sāmoa since the I960s (Macpherson, Bedford, and Spoonley 2000). However, only in Micronesia does the longitudinal pattern of suicide rates from the I960s to the early 2000 s fit a tale of persistent social disequilibrium. The dramatic decline in suicide rates in Sāmoa since the early I980s is inconsistent with the social disequilibrium theory. ${ }^{9}$ These contrasting cases suggest that the social disequilibrium explanation could not be a general explanation for suicide and social change in island nations of Oceania, like Sāmoa and in the Micronesian region, if not elsewhere.

\section{Assessing the Evidence Associated with Social Disintegration Explanation}

There are no data available from Sāmoa to assess the claims given in the social disintegration explanation described above. But there are data for Micronesia. Specifically, the longitudinal census data can be used to assess whether there is a trend from the early USTTPI period and later (ie, the I950s to the I980s and beyond) toward family nuclearization, the central claim in the social disintegration thesis. In the censuses from the late I950 through to 2000, statistics for household composition are given that report the familial relationship to the household head in terms of spouses, children, parents, grandchildren, and other unspecified relatives. These statistics can be used to examine any change in the overall trend toward greater nuclearization of households over time. Specifically, we would expect a decline in the presence of household members other than those that would represent a nuclear family structure (eg, parents of the householder, grandchildren, siblings, siblings' children, affinal kin, etc) in households from the late 1950 os to the present. For the island groups across the USTTPI in 1958, 28 percent of household members were listed as parents, grandchildren, or "other relatives" of the householder, and 
most of these (I9 percent) were "other relatives" (non-nuclear extended kin). By I980, 26 percent of household members were "other relatives" of the householder, increasing to 29 percent in 2000 , the most recent year for which such data are available (FSM Division of Statistics 2002). In 2000, the lowest percentage of extended kin living in households was for Palau at 26 percent and the highest was in the Marshall Islands at 36 percent (Palau Office of Planning and Statistics 2005; Republic of the Marshall Islands 20II). As a point of comparison, in the 2010 US census, only 7 percent of household members were related to the householder as extended kin. Therefore, the speculation concerning family nuclearization in response to modernization and globalization in the Micronesian region is not supported. Micronesian households appear to be as complex in the present as they were prior to the onset of the current period of modernization. A constant rate of household complexity cannot explain sharply increasing suicide rates from the I960s through the I980s, as available data do not support the claim that there was a widespread household nuclearization after the I960s in Micronesia.

Ethnographic evidence also runs contrary to the claims of social disintegration in Micronesia. Overall, several relatively recent studies of kinship practices in Micronesia present a picture of innovation and resiliency as core kinship principles that are common throughout the region, like the primacy of cooperative sibling ties, a matrilineal bias for the lineage membership of offspring, inheritance of property, group identity, and clan membership are creatively adapted to new circumstances as these islands participate in both local and translocal practical, political, and economic currents (Burton, Nero, and Egan 200I; Carucci 1997; Lowe 2002, 2003; Marshall 1999). It is likely that this adaptive flexibility of core kinship structures that are common across the Micronesian region has been essential for survival in these small island ecologies, which are located in a climatologically volatile region that has been prone to extended periods of drought and frequent tropical storms and typhoons for centuries (Petersen 2009). This adaptive flexibility of Micronesian kinship may also be key to surviving the boom and bust cycles associated with the region's ongoing participation in the globalizing world order under several colonial regimes since the mid-nineteenth century. Macpherson described a similar pattern of innovation and accommodation in kinship practices in Sāmoa because of its greater participation in the globalizing political-economic system since the mid-nineteenth century, rather than clear patterns of social disintegration and outright 
dispossession and displacement of local cultural forms (I999; see also Macpherson and Macpherson 2009).

Overall, then, one finds little consistent support in these empirical data for some of the major claims of either social disequilibrium or social disintegration as a general explanation for the suicide epidemics in Sāmoa and the Micronesian region. But there are some compelling alternative explanations to consider that do have empirical support, which I discuss briefly in the next section.

\section{Alternative Explanations: Globalization, (Post)Colonial Policies, and Relational Dynamics}

One alternative explanation that fits the acute rise in suicide rates for Sāmoa starting in the I970s suggests that it was primarily the result of an adoption of a particularly lethal means of attempting suicide that became available because of Sāmoa's incorporation into globalizing commodity markets and local agricultural development policies (Bowles I985, 1995). To understand this explanation, some background on the phenomena of suicide in Sāmoa is needed. Suicidal behavior in Sāmoa is rarely associated with prolonged mental illness or mood disturbances like major depression. Suicides are rarely planned in advance; rather, they tend to be impulsive acts in response to sudden or ongoing interpersonal tension or familial conflict (Macpherson and Macpherson I987, 2009). Generally, suicidal behavior reflects a form of protest (Hollan I990), or what Edward Hagen, Paul Watson, and Peter Hammerstein have called "costly signaling" in an attempt to gain renewed sympathy and support from family members in the immediate aftermath of some deeply felt personal slight, act of neglect, or shameful exposure (Hagen, Watson, and Hammerstein 2008). A suicide attempt may not represent an intention to actually kill oneself so much as an impulsive strategy of self-harm as a means of negotiating critical interpersonal conflicts, almost always within the local kin group.

The lethality of the means collectively chosen for such costly signaling can be a critical factor in shaping overall suicide rates. In Sāmoa, ingesting a poisonous substance is the most common strategy of self-harm (Bowles I995; Samoa Ministry of Health 2005). Paraquat, a highly toxic herbicide, became increasingly and widely available in Sāmoa as a result of an aggressive global marketing campaign by its manufacturer and through Samoan government subsidy and distribution in the I970s. Lethal suicidal attempts by paraquat ingestion increased in direct association. In I98 I, 
paraquat poisoning was associated with 40 of 49 ( 82 percent) recorded deaths by suicide in Sāmoa and 34 of 45 (75.5 percent) nonlethal suicide attempts (Bowles I985). John Bowles has shown further that as government funding for paraquat importation and distribution declined sharply in Sāmoa in the early I980s, so too did the suicide mortality rate (I995). Since the I980s, the preference for paraquat ingestion as a method of attempting suicide has also declined. The Samoa Ministry of Health reported that paraquat poisonings remained the most common method for attempted suicide and death by suicide between 2000 and $2005-46$ percent of 97 cases reported to the two main hospitals during this period (2005). But paraquat use had declined from 82 percent of cases in $\mathrm{I} 98 \mathrm{I}$ to 47 percent of cases in the 2000 to 2005 period. Coupled with the decline in suicide rates overall in Sāmoa since the I980s, this suggests that more recent youth cohorts may have switched to less lethal means of costly signaling in Sāmoa.

In the Micronesian context, the interpersonal and emotional circumstances surrounding suicide attempts are nearly identical to the general pattern reported for Sāmoa (Lowe 2003; Rubinstein I983, I995). While less lethal means of self-harm for such costly signaling have been reported across Micronesia-like threatening to throw oneself from the top of a coconut tree, attempting to drown oneself in the presence of others, or refusing to eat (Gladwin and Sarason 1953; Rubinstein 1992) - the great majority of suicidal deaths are the result of intentional hanging, and death by poisoning is quite rare (Rubinstein 1983). The suicide epidemic in Micronesia, then, is not the result of a poisonous global commodity like paraquat becoming increasingly available. The picture for the Micronesian region is further complicated by the great diversity of contexts across which the epidemic has been taking place, including a complex mix of high volcanic islands and low-lying coral atolls, nine distinct language groups, and a complex array of social organizational and political economic arrangements both before and after successive waves of colonial control. Although there may be a distinctly Micronesian cultural and social organizational substrate across the region that has historically deep roots (Petersen 2009), there is nothing like the greater cultural homogeneity of the Samoan case.

Yet, the suicide epidemic runs through the Micronesian region in a consistent fashion, from the Marshall Islands in the east to Palau in the west. Moreover, rates have remained stubbornly high by world standards until at least the early 2000s. I agree with Hezel (1987, I989) that the suicide 
epidemic in Micronesia is an indirect consequence of US development policy in the region from the late I960s on, particularly regarding the sudden increase in the availability of US dollars in the form of direct development investment through the US Trust Territory of the Pacific Islands from the I960s through the I970s (Lowe 2003, 2017, 2018; see also Weisner and Lowe 2004; see figure I). But I also suggest that it is how the rapid influx of money fueled and intensified discordant local practices that at least in part accounts for the suicide epidemic across the region (Lowe 20I8). The ethnographic record shows that Micronesians taking advantage of the increasing availability of dollars to purchase imported commodities to be used in intensified rounds of competitive ritual feasting, church and lineage or local political building construction, and the production and ownership of a host of lifestyle items, from imported clothing to radios,

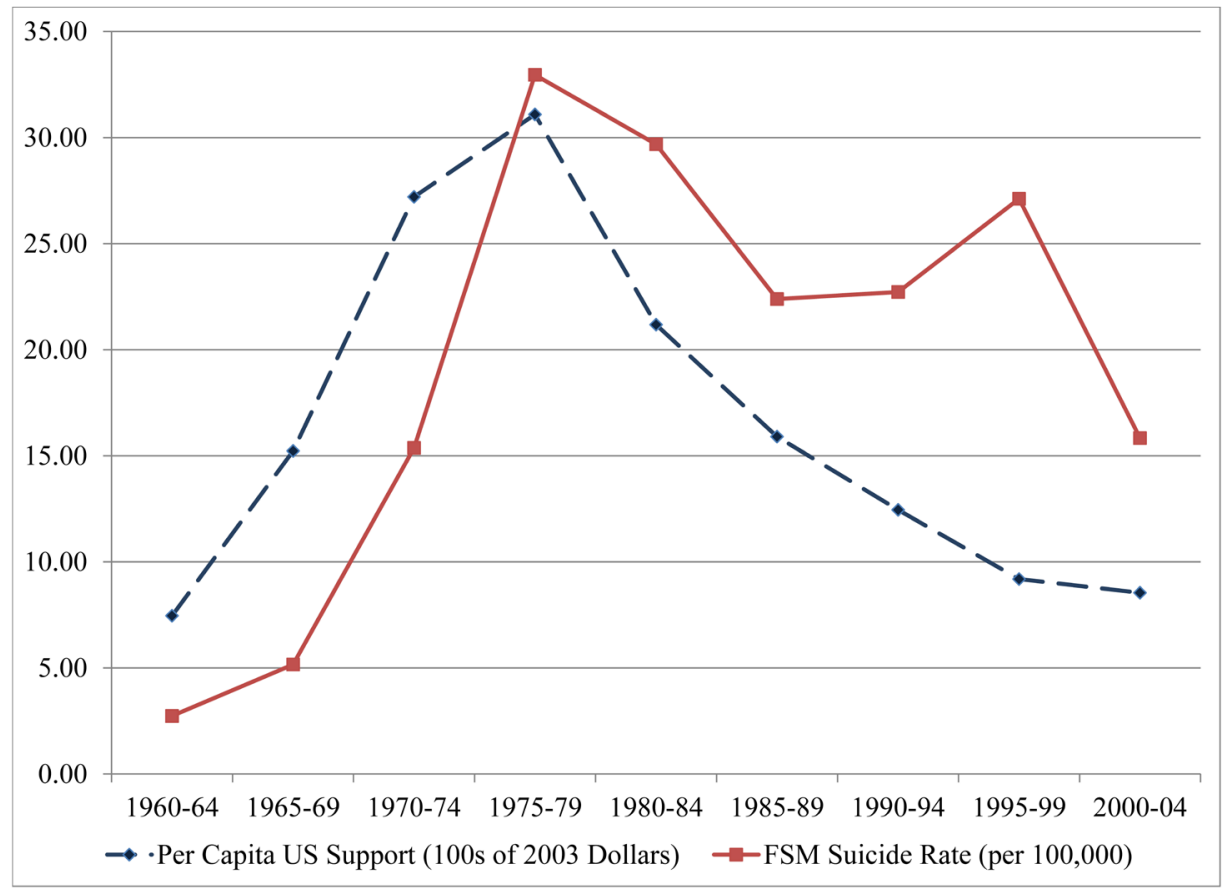

Figure I Historical Suicide Rates and Annual Dollar Amounts of US Direct Aid per capita to the Federated States of Micronesia (I960-2003)

Sources for FSM suicide rates: Hezel I989; Booth I999b; author's calculations. Sources for US support: Office of Micronesian Status Negotiations I984; USTTPI I987; Asian Development Bank 2005. 
televisions, and VCRs, and now, cell phones and laptop computers. At the same time, young people were innovating new lifestyles that reflected globalization, but in locally meaningful forms. Older boys' and young men's use of tobacco, drugs, and alcohol, as well as increased peer-to-peer fighting and other acts of bravado that are glorified in globally circulated popular action movies, and other important means of identity formation in the peer group have become particularly troublesome. Family and wider community disapproval of aspects of these youth lifestyles are often a source of tension and familial conflict that precede suicide attempts (Lowe 2003; Marshall 1979, Rubinstein I995; Weisner and Lowe 2004). Moreover, the constant public condemnation of some of these lifestyle behaviors by religious and government authorities only serves to worsen these tensions. I argue that, in comparison with the Samoan case, the Micronesian suicide epidemic could be a more intense reflection of increased distress among youth, particularly older boys and young men, and their families over the competing demands of these new, and at times divergent, identity projects (Lowe 2003, 2018). Further empirical research is needed to test this hypothesis.

\section{Conclusion: Toward More Appropriate AND Useful Explanatory ACCOUNTS}

This article suggests that, rather than adopting the Western explanation that suicide epidemics are the inevitable outcome of social disequilibria or social disintegration accompanying modernizing social change, it would be more useful to examine a wider range of processes associated with globalization and modernization that can worsen vulnerabilities and strengthen resiliencies in different contexts. Much of the literature that emerged to explain the suicide epidemics in Oceania in the late twentieth and early twenty-first centuries follows the model developed by nineteenth-century theorists of modernity quite closely, mostly reproducing theories of social disequilibrium or social disintegration to explain the suicide epidemics in many islander societies of Oceania. In contrast, the empirical evidence shows that, although policies of modernization may have been rather widespread, vulnerable population risks to suicide were highly variable. Therefore, a general theory of modernizing social change and vulnerability to suicide epidemics is not appropriate. More contextspecific explanations are needed.

For example, in the Samoan case, the brief but intense suicide epidemic 
among youth during the I970s and I980s might reflect how a globalized commodity, the herbicide paraquat, was appropriated by young people as a means of protest suicidality, in a setting where there was a long history of intoxicant and toxin use as a means of engaging in a form of costly signaling to help redress acute relational slights and grievances in the family. This resonates with other anthropological studies of the dynamic transformations of substances as they move between global processes of commodification and local forms of meaningful use in social relations (Geissler and Prince 2009; Besnier 20II). In this context, the sudden appropriation of an unfamiliar, highly toxic global commodity can contribute to a rapid increase in suicide rates. But a focus on the "social change" narrative, while easily recognized by scholars raised on a steady diet of social change narratives through formal training in mid-twentieth-century sociology and anthropology, directs attention away from potentially useful social policy recommendations (such as more careful monitoring and control of lethal industrial toxins) and toward conservative ideological positions that emphasize either greater efforts toward "modernization" or a rediscovery and institutionalization of a society's historically durable traditions (eg, Hau'ofa I994).

On the other hand, the sudden increased risk and sustained high levels of youth suicide across the Micronesian region is strongly correlated with the changing levels of development assistance from the United States beginning in the late I960s. What is conspicuous about this period is how a sudden increase in the availability of US dollars in the local economies of the region fueled the competitive incorporation of global consumer commodities into new global-local hybrid lifestyles, particularly in the urbanizing port towns and nearby peri-urban regions. One promising avenue of research into the Micronesian context would be to examine how finance flows that are the direct consequence of the particular approach to modernization undertaken by the United States-an approach that emphasizes commodity consumption over productive capital investment-led to a sort of inflation in the costs associated with social status competitions among families, kin groups, and political elites in the region (Lowe 20I 8). At the same time, the increase in cash meant that young men in particular were able to explore new lifestyles associated with commodity consumption, most problematically the abuse of alcohol, tobacco, and betel nut as an aspect of contemporary identity projects (Marshall I979). The Micronesian case, therefore, points to a very different policy focus in terms of addressing the suicide problem from the Samoan case. It points to how 
the dramatic infusion of cash into local economies can fuel forms of status inflation, lifestyle change, and increased intergenerational conflicts and suggests that economic policies directed toward the local development of productive capital might be preferable to the creation of a consumerdriven welfare society.

The points raised in the two preceding paragraphs emphasize the importance of a perspective that recognizes the role of "relationships and relational spaces" (Mila 2016, 63) and a great variety of local-global mobilities that occur within those spaces are for a better understanding of suicide and other important social problems for Oceanic peoples (Lilomaiava-Doktor 2009). Throughout Oceania, traditional understandings of health and well-being emphasize just such a perspective of relationship and relational spaces, or a perspective of the vā or wā, understood as "the space where the reciprocal flow of relating occurs" (Mila 2016, 70; also Mila-Schaaf 2006). The argument I make here is that the late twentiethcentury suicide epidemics in Sāmoa and Micronesia (and likely elsewhere) were also rooted in tensions present within such relational spaces that are so important in the everyday lives of Oceanic people. This view contrasts with the Western academic sociological perspective that has been appropriated regularly to explain social problems and suicide among Pacific Islander youth in the region.

My argument, then, supports the projects of scholars and practitioners who are "re-engaging with . . . an indigenous reference that has much to tell us about healing, wholeness and aetiology and treatment" (Mila 2016, 75 ). Drawing on these indigenous perspectives can help build programs that are more responsive to Pacific Islanders who are suffering from a range of social problems. But such a project also requires an equal, reflexive, and critical treatment of perspectives rooted in Western traditions that dominate both scholarship and practice in many contexts across the region, such as the one given in this article.

In closing, I should note that we should be cautious about overgeneralizing from some of the claims made in my argument. For example, the use of census data to assess some of the earlier explanations given for suicide epidemics in places like Sāmoa and the Micronesian region is, at best, suggestive. More systematic statistical analyses are needed to better test the arguments (eg, Lowe 20I8). Also, the analysis here is illuminative of Sāmoa and the Micronesian region but may be limited to these two. How the arguments given above might translate to other contexts in the Pacific Islands region must be the subject of further empirical research. Further, 
the discussion in this article has not taken up the question of the positive effects of social change associated with modernization and globalization in the lives of young people and their families, not the least of which is the unprecedented opening-up of possibilities for enhanced mobility, connection, and the pursuit of rewarding life projects that earlier generations could not have imagined. The opening of possibilities has almost certainly been the most dramatic for girls and women (Booth I 999a). Research into how these more positive dimensions of modernizing social change might be protective regarding the mental health vulnerabilities of Pacific Islanders is urgently needed. Finally, new studies are also needed to examine how local, enduring, or resurgent cultural values and practices in the Pacific Islands region can also be protective, as these are certainly as important in Islanders' lives as in those of the emerging global society.

Harold Odden, Fran Hezel, Shane Barter, and two anonymous reviewers provided very helpful feedback on earlier versions of this manuscript. Ms Alexis Houghton helped with an exhaustive literature search on studies of suicide in Oceania up to 20I5. I am also indebted to Fran Hezel and the Micronesian Seminar both for access to Micronesian suicide data and for many years of support and advice as this project developed. I cannot express enough gratitude to the late $\mathrm{Mr}$ Amanisio Joseph and members of his lineages for patiently helping me to understand these issues from a Micronesian perspective over the course of two decades. Portions of this research were supported by a summer faculty research grant from the Pacific Basin Research Center at Soka University of America. I have no conflicts of interest to declare.

\section{Notes}

I These include the Republic of Palau, the Federated States of Micronesia, the Republic of the Marshall Islands, and the Commonwealth of the Northern Mariana Islands.

2 Booth I999a, I999b; Hezel I987; Lowe 2003, 2017, 2018; Macpherson and Macpherson 1987, 2009; McDade and Worthman 2004; Roberts 2007; Rubinstein 1983, I992.

3 Since that time, explicit sociological and anthropological attention has declined, with few new publications that examine changing suicide rates appearing after 2010 (eg, Booth 20I0; Lowe 20I8).

4 Booth I999a, I999b, 2010; Haynes 1984; Hezel 1987; Macpherson and 
Macpherson I987, 2009; McDade and Worthman 2004; Rubinstein I983, I992, 2002.

5 Booth I999a, I999b; Haynes I984; Macpherson and Macpherson I987, 2009; McDade and Worthman 2004; O’Meara I990.

6 Crude suicide rates are calculated as the number of suicides per unit population. Crude rates are not adjusted given the distribution of suicide by age-group.

7 Micronesian rates from I960 to 1987 are taken from Hezel I989, those from I988-I992 are taken from Booth I999. The rates from I992 to 2005 are crude estimates based on case data made available from the Micronesian Seminar, a Jesuit-run social welfare organization that has been collecting community-level suicide case data since the I970s, with the most recent data collection effort in 2007 (Hezel, pers comm, 2008). The unstandardized suicide rates for Sāmoa are based on data available in Macpherson and Macpherson 1987 for the period from I970 to I982, Bourke 2001 for the period from I983 to 2000 , and the Samoa Ministry of Health 2005 for the period from 200I to 2005 .

8 There is some evidence that the differential patterns reported here also reflect trends for migrant diasporas in Guam and New Zealand. For example, Booth reported that “Guam's crude suicide rate of I9 per I00,000 in I998-2002 is inflated by about $16 \%$ due to the presence of FSM migrants" (2010, 7). Booth reported a suicide rate of 9I per Ioo, 000 for FSM people on Guam compared to the overall rate of I9 for Guam for this period. That is a stunning disparity. Contrastingly, the New Zealand Ministry of Health reported "that Pacific peoples commit suicide at a rate of 8.3 per ı००,००० Pacific peoples, compared with I 4 per I००,০০০ for New Zealand overall” (2008, I 5 ) during that same period. Samoans made up 49 percent of the "Pacific peoples" category in that report. Another 2 I percent were Cook Islands Māori, and I6.5 percent were Tongan.

9 Although they should be read with some caution because of less-than-perfect overlap in measures across the different points in time, the patterns just reviewed show that while educational attainment had been increasing across Micronesia from the start of major US development programs in the I96os to at least the end of the millennium (FSM Division of Statistics 20I2), the mix of wage/salary and subsistence and local agricultural employment has stayed at nearly the same levels when adjusted for population growth for decades.

\section{References}

Arnett, Jeffrey

2002 The Psychology of Globalization. American Psychologist 57 (IO): $774-783$.

Asian Development Bank

2005 Federated States of Micronesia 2005: Economic Report. Pacific Islands Series. Manila: Asian Development Bank. 
Besnier, Niko

20II On the Edge of the Global: Modern Anxieties in a Pacific Island Nation. Stanford, CA: Stanford University Press.

Booth, Heather

I999a Gender, Power and Social Change: Youth Suicide among Fiji Indians and Western Samoans. The Journal of the Polynesian Society Io8 (I): 39-68.

I999b Pacific Island Suicide in Comparative Perspective. Journal of Biosocial Science 3 I (4): 433-448.

20 I0 The Evolution of Epidemic Suicide on Guam: Context and Conta-

Bourke, Terry gion. Suicide \& Life-Threatening Behavior 40 (I): I-I3.

$200 \mathrm{I}$ Suicide in Samoa. Pacific Health Dialog 8 (I): 2I3-2I9.

Bowles, John

I985 Suicide and Attempted Suicide in Contemporary Western Samoa. In Culture, Youth and Suicide in the Pacific: Papers from an East-West Center Conference, edited by Francis X Hezel, Donald H Rubinstein, and Geoffrey M White, I 5-35. Occasional Paper Series 25. Honolulu: Pacific Islands Studies Program, Center for Asian and Pacific Studies, University of Hawai'i at Mānoa.

I995 Suicide in Western Samoa-An Example of a Suicide Prevention Programme in a Developing Country. In Preventative Strategies on Suicide, edited by Rene F W Diekstra, Walter Gulbinat, Ineke Kienhorst, and Diego de Leo, I73-206. Leiden, NL: Brill Academic Publishers.

Browne, Colette V, Noreen Mokuau, Lana S Ka'opua, Bum Jung Kim, Paula Higuchi, and Kathryn L Braun

20I4 Listening to the Voices of Native Hawaiian Elders and 'Ohana Caregivers: Discussions on Aging, Health, and Care Preferences. Journal of Cross-Cultural Gerontology 29 (2): I3 I-I 5 I.

Burton, Michael L, Karen L Nero, and James A Egan

$200 \mathrm{~T}$ The Circulation of Children through Households in Yap and Kosrae. Ethos 29 (3): 329-356.

Carucci, Laurence

I997 Nuclear Nativity: Rituals of Renewal and Empowerment in the Marshall Islands. DeKalb: Northern Illinois University Press.

Counts, Dorothy

I984 Revenge Suicide by Lusi Women: An Expression of Power. In Rethinking Women's Roles: Perspectives from the Pacific, edited by Denise O'Brien and Sharon W Tiffany, 7I-93. Berkeley: University of California Press.

Durkheim, Émile

I95 I Suicide: A Study in Sociology. Translated by John A Spaulding and 
George Simpson. Edited by George Simpson. Glencoe, IL: Free Press. Originally published in $\mathrm{I} 897$.

Firth, Stewart

2000 The Pacific Islands and the Globalization Agenda. The Contemporary Pacific I2 (I): I78-I92.

FSM Division of Statistics

2002 The FSM 2000 Census of Population and Housing. Palikir, Pohnpei: Department of Economic Affairs, FSM National Government, Federated States of Micronesia.

2012 Summary Analysis of Key Indicators from the FSM 2010 Census of Population and Housing. Palikir, Pohnpei: Department of Economic Affairs, FSM National Government, Federated States of Micronesia.

Gegeo, David, and Karen Ann Watson-Gegeo

I985 Patterns of Suicide in West Kwara'ae, Malaita, Solomon Islands. In Culture, Youth and Suicide in the Pacific: Papers from an East-West Center Conference, edited by Francis X Hezel, Donald H Rubinstein, and Geoffrey M White, I 82-I97. Occasional Paper Series 25. Honolulu: Pacific Islands Studies Program, Center for Asian and Pacific Studies, University of Hawai'i at Mānoa.

Geissler, P Wenzel, and Ruth J Prince

2009 Active Compounds and Atoms of Society: Plants, Bodies, Minds and Cultures in the Work of Kenyan Ethnobotanical Knowledge. Social Studies of Science 39 (4): 599-634.

Giddens, Anthony J

I965 The Suicide Problem in French Sociology. The British Journal of Sociology I6 (I): 3-I 8 .

Gladwin, Thomas, and Seymour B Sarason

I953 Truk: Man in Paradise. Viking Fund Publications 20. New York:

Wenner-Gren Foundation for Anthropological Research, Inc.

Hacking, Ian

I990 The Taming of Chance. Cambridge, uk: Cambridge University Press.

Hagen, Edward H, Paul J Watson, and Peter Hammerstein

2008 Gestures of Despair and Hope: A View on Deliberate Self-Harm from Economics and Evolutionary Biology. Biological Theory 3 (2): I $23-\mathrm{I} 38$.

Hau'ofa, Epeli

I994 Our Sea of Islands. The Contemporary Pacific 6 (I): I48-I6I. Haynes, Ruth H

I984 Suicide in Fiji: A Preliminary Study. British Journal of Psychiatry I 45 (4): $433-438$.

Hezel, Francis X

I976 Micronesia's Hanging Spree. Micronesian Independent, 3 I Dec. 
I977 Suicide Epidemic among Micronesian Youth. South Pacific Bulletin 27 (2): 5-IO.

I987 Truk Suicide Epidemic and Social Change. Human Organization 46 (4): 283-29I.

I989 Suicide and the Micronesian Family. The Contemporary Pacific I (I\&2): 43-74.

I995 Strangers in Their Own Land: A Century of Colonial Rule in the Caroline and Marshall Islands. Pacific Islands Monograph Series I3. Honolulu: University of Hawai'i Press.

Hollan, Douglas

I990 Indignant Suicide in the Pacific: An Example from the Toraja Highlands of Indonesia. Culture, Medicine and Psychiatry I4 (3): 365379 .

Kuper, Adam

2005 The Reinvention of Primitive Society: Transformations of a Myth. Second edition. London: Routledge Press.

Lilomaiava-Doktor, Sa'iliemanu

2009 Beyond "Migration": Samoan Population Movement (Malaga) and the Geography of Social Space (Vā). The Contemporary Pacific 2 I

Lowe, Edward (I): I-32.

2002 A Widow, a Child, and Two Lineages: Exploring Kinship and Attachment in Chuuk. American Anthropologist IO4 (I): I23-I37.

2003 Identity, Activity, and the Well-Being of Adolescents and Youths: Lessons from Young People in a Micronesian Society. Culture, Medicine and Psychiatry 27 (2): I87-219.

20I7 Rapid Societal Change and Mental Health Vulnerabilities in the Pacific Basin. In The Pacific Basin: An Introduction, edited by Shane J Barter and Michael Weiner, I68-I76. London: Routledge.

20I 8 Social Change and Micronesian Suicide Mortality: A Test of Competing Hypotheses. Cross-Cultural Research, 28 Feb. doi.org/ıo .I I 77/I069397 I I 8759004

Macpherson, Cluny

I999 Changing Contours of Kinship: The Impacts of Social and Economic Development on Kinship Organization in the South Pacific. Pacific Studies 22 (2): 7 I-95.

Macpherson, Cluny, and La'avasa Macpherson

I987 Towards an Explanation of Recent Trends in Suicide in Western Samoa. Man 22:305-330.

2009 The Warm Winds of Change: Globalisation in Contemporary Sāmoa. Auckland: Auckland University Press. 
Macpherson, Cluny, Richard Bedford, and Paul Spoonley

2000 Fact or Fable? The Consequences of Migration for Educational Achievement and Labor Market Participation. The Contemporary Pacific I 2 (I): 57-82.

Marsella, Anthony J, Ayda Aukahi Austin, and Bruce A Grant 2005 Some Closing Comments. In Social Change and Psychosocial Adaptation in the Pacific Islands: Cultures in Transition, edited by Anthony Marsella, Ayda Aukahi Austin, and Bruce Grant, 273-300. New York: Springer.

Marshall, Mac

I979 Weekend Warriors: Alcohol in a Micronesian Culture. Palo Alto, CA: Mayfield Publishing Company.

I999 Partial Connections: Kinship and Social Organization in Micronesia. In American Anthropology in Micronesia: An Assessment, edited by Robert Kiste and Mac Marshall, I07-I43. Honolulu: University of Hawai'i Press.

McDade, Thomas W, and Carol M Worthman

2004 Socialization Ambiguity in Samoan Adolescents: A Model for Human

Development and Stress in the Context of Culture Change. Journal of Research on Adolescence I4 (I): 49-72.

Mila, Karlo 2016 Mana Moana: Healing the Vā, Developing Spiritually and Culturally Embedded Practices. In Practising Spirituality, edited by Laura Béres, 6I-78. London: Palgrave.

Mila-Schaaf, Karlo

2006 Vā-Centered Social Work: Possibilities for a Pacific Approach to Social Work Practice. Social Work Review (Ti Mau II) I 8 (I): 8-I3.

Morselli, Enrico

I879 Il Suicidio: Saggio di Statistica Morale Comparata. Milan: Fratelli Dumolard.

New Zealand Ministry of Health

2008 Pacific Peoples and Mental Health: A Paper for the Pacific Health and Disability Action Plan Review. Wellington: Ministry of Health.

NYT, New York Times

I962 Enthusiastic Trustee: Jose Benito Alvarez. I 2 Feb.

Office for Micronesian Status Negotiations

I984 Draft Environmental Impact Statement for the Compact of Free Association. Washington, DC: US Department of State.

O’Meara, Tim

I990 Samoan Planters: Tradition and Economic Development in Polynesia. Fort Worth, Tx: Holt, Rinehart and Winston. 
Palau Office of Planning and Statistics

20052005 Census of Population and Housing of the Republic of Palau. Koror, Palau: Palau Office of Planning and Statistics.

Peltzer, Karl, and Supa Pengpid

20I 5 Early Substance Use Initiation and Suicide Ideation and Attempts among School-Aged Adolescents in Four Pacific Island Countries in Oceania. International Journal of Environmental Research and Public Health I2 (IO): I229I-I 2303.

Petersen, Glenn

2009 Traditional Micronesian Societies: Adaptation, Integration, and Political Organization in the Central Pacific. Honolulu: University of Hawai'i Press.

Poole, Fitz John Porter

I985 Among the Boughs of the Hanging Tree: Male Suicide among the Bimin-Kuskusmin of Papua New Guinea. In Culture, Youth and Suicide in the Pacific: Papers from an East-West Center Conference, edited by Francis X Hezel, Donald Rubinstein, and Geoffrey White, I 52-I8I. Occasional Paper Series 25. Honolulu: Pacific Islands Studies Program, Center for Asian and Pacific Studies, University of Hawai'i at Mānoa.

Republic of the Marshall Islands

2OII The RMI 201 I Census of Population and Housing: Summary and Highlights Only. Majuro, RMI: Office of Economic Policy, Planning, and Statistics.

Roberts, Graham

2007 Masculinity, Mental Health and Violence in Papua New Guinea, Vanuatu, Fiji and Kiribati. Pacific Health Dialog I4 (2): 35-4I.

Rubinstein, Donald H

I983 Epidemic Suicide among Micronesian Adolescents. Social Science and Medicine I7 (I0): 657-665.

I992 Suicide in Micronesia and Samoa: A Critique of Explanations. Pacific Studies I 5 (I): 5 I-75.

I995 Love and Suffering: Adolescent Socialization and Suicide in Micronesia. The Contemporary Pacific 7 (I): 2 I-53.

2002 Youth Suicide and Social Change in Micronesia. Occasional Papers 36. Kagoshima, Japan: Kagoshima University Research Center for the Pacific Islands.

Samoa Bureau of Statistics

20II Population and Housing Census 20II: Analytical Report. Apia: Samoa Bureau of Statistics.

Samoa Ministry of Health

2005 Annual Report 2004-2005. Apia: Government of Sāmoa. 
Schlegel, Alice

I995 A Cross-Cultural Approach to Adolescence. Ethos 23 (I): I 5-32.

2013 Conclusion: Perspectives on Adolescent Identity. In Adolescent Identity: Evolutionary, Cultural and Developmental Perspectives, edited by Bonnie L Hewlett, 30I-3 I 8. London: Routledge.

Schoeffel, Penelope

I979 Daughters of Sina: A Study of Gender, Status, and Power in Western Samoa. PhD thesis, The Australian National University.

Simmel, Georg

2002 The Metropolis and Mental Life. In The Blackwell City Reader, edited by Gary Bridge and Sophie Watson, II-I9. Malden, MA: Wiley Blackwell. Originally published in I903.

Stewart-Withers, Rochelle R, and Anthony P O'Brien

2006 Suicide Prevention and Social Capital: A Samoan Perspective. Health Sociology Review I 5 (2): 209-220.

Taualii, M, J Quenga, R Samoa, S Samanani, and D Dover

20I I Liberating Data: Accessing Native Hawaiian and Other Pacific Islander Data from National Data Sets. AAPI Nexus: Asian Americans \& Pacific Islanders Policy, Practice and Community 9 (I-2): 249-255.

Taualii, Maile, Elise Leimoni Davis, Kathryn L Braun, Joann Umilani Tsark, Ngiare Brown, Maui Hudson, and Wylie Burke

2014 Native Hawaiian Views on Biobanking. Journal of Cancer Education 29 (3) 570-576.

Taualii, Maile, Trina Delormier, and Jay Maddock

20I3 A New and Innovative Public Health Specialization Founded on Traditional Knowledge and Social Justice: Native Hawaiian and Indigenous Health. Hawai'i Journal of Medicine \& Public Health 72 (4): I43.

Tousignant, Michel

I998 Suicide in Small-Scale Societies. Transcultural Psychiatry 35 (2): $29 \mathrm{I}-306$.

US Bureau of the Census

[1984] I980 Census of the Population. Volume I, Characteristics of the Population. Chapter C/D, Detailed Social and Economic Characteristics. Part ${ }_{57} \mathrm{~B}$, The Trust Territory of the Pacific Islands excluding the Northern Mariana Islands. Washington, DC: Commerce Department.

UsTTPI, United States Trust Territory of the Pacific Islands

I958 Census of the Trust Territory of the Pacific Islands. Office of the High Commissioner. Washington, DC: United States Department of Insular Affairs. 
I987 42nd Annual Report to the United Nations on the Administration of the Trust Territory of the Pacific Islands, I October I986-30 September 1987. Washington, DC: US Department of State.

Ward, Martha

2004 Nest in the Wind: Adventures in Anthropology on a Tropical Island. Second edition. Long Grove, IL: Waveland Press.

Weisner, Thomas S, and Edward Lowe

2004 Globalization, Childhood, and Psychological Anthropology. In A Companion to Psychological Anthropology: Modernity and Psychocultural Change, edited by Conerly Casey and Robert B Edgerton, 3I 5-336. Malden, MA: Blackwell Publishing.

World Health Organization

I999 Figures and Facts about Suicide. Geneva: World Health Organization.

20I4 Preventing Suicide: A Global Imperative. Geneva: World Health Organization.

\section{Abstract}

This article examines the Western academic explanations for suicide epidemics among adolescents and young adults documented in many Pacific Island nations beginning in the early I970s. These explanatory accounts draw heavily from Émile Durkheim's theory of social change and suicide, developed in the late nineteenth century. Durkheim argued that suicide epidemics are more likely in the context of modernizing social change either because of increased social disequilibrium (anomie) or social disintegration (egoism). These traditional Western explanations are rarely empirically assessed for their appropriateness in Pacific Island contexts. Therefore, this article uses selected empirical evidence to assess the major claims found in these explanations, focusing on Sāmoa and the Micronesian region as the best documented examples. Finding that the data do not support well the major Western-derived explanations for these suicide epidemics, alternative explanations are explored. These alternatives suggest that Pacific Island young people's vulnerability to suicide is partly a result of how globalizing commodity flows, development policies, and the selective appropriation of these by local actors inform local social relations and the tensions in them. This view supports well recent advocacy for a shift in perspectives toward those that draw on indigenous Oceanic understandings of the vā or wā as relational spaces that are central for the quality of health and well-being in Pacific Island communities.

KEYwORDS: social change, youth, suicide, Federated States of Micronesia, Republic of the Marshall Islands, Republic of Palau, Sāmoa 